\title{
Effect of Distance from Target on Hypopituitarism After Stereotactic Radiosurgery for Pituitary Adenomas
}

\section{Natasha Ironside}

University of Virginia Health System https://orcid.org/0000-0002-9390-1574

Harrison Snyder

Tufts University

\section{Zhiyuan Xu}

University of Virginia Health System

\section{David Schlesinger}

University of Virginia

\section{Ching-Jen Chen}

Thomas Jefferson University - Center City Campus

\section{Mary Lee Vance}

University of Virginia

\section{Gregory K. Hong}

University of Vienna Konrad Lorenz Research Station

\section{John A. Jane}

University of Virginia

Jason P. Sheehan ( $\sim$ jsheehan@virginia.edu )

University of Virginia

\section{Research Article}

Keywords: stereotactic radiosurgery, gamma knife radiosurgery, pituitary adenoma, hypopituitarism, endocrinopathy, distance, dose

Posted Date: November 22nd, 2021

DOI: https://doi.org/10.21203/rs.3.rs-1037768/v1

License: (c) (i) This work is licensed under a Creative Commons Attribution 4.0 International License. Read Full License

Version of Record: A version of this preprint was published at Journal of Neuro-Oncology on April 24th, 2022. See the published version at https://doi.org/10.1007/s11060-022-04007-6. 


\section{Abstract}

\section{Introduction}

Delayed hypopituitarism is the most common complication after stereotactic radiosurgery (SRS) for pituitary adenomas. The aim of this study was to investigate the relationship between the distance from the hypothalamicpituitary axis to the treatment target and anterior pituitary function preservation after SRS.

\section{Methods}

Between 2007 and 2020, consecutive adult patients who underwent single-session SRS for pituitary adenomas with ${ }^{3} 6$ months of follow-up were included. Distance measurements between hypothalamic-pituitary axis structures and the SRS target volume were quantified on MRI. The primary outcome was anterior pituitary function preservation. Outcomes were compared using multivariable regression and area under the receiver operator characteristic curve (AUROC) analyses.

\section{Results}

The study cohort comprised 224 patients, who were categorized by preservation $(n=168)$ and no preservation $(n=56)$ of anterior pituitary function after SRS. Independent predictors of anterior pituitary function preservation were a greater distance between the center of the pituitary gland and center of the SRS target (OR=1.101 [1.0001.213], $p=0.050)$, and a shorter clinical follow-up duration ( $O R=0.985$ [0.977-0.993], $p<0.0001)$. The adjusted AUROC for the distance from the center of the pituitary gland and center of the SRS target in predicting anterior pituitary function preservation was 0.595 . The sensitivity, specificity, positive predictive value and negative predictive value in predicting anterior pituitary function preservation at the optimal cut-off distance of $15 \mathrm{~mm}$ were $30.0 \%, 88.0 \%, 89.9 \%$ and $26.2 \%$, respectively.

\section{Conclusions}

Greater distance between the normal pituitary gland and the SRS target is associated with anterior pituitary function preservation and increasing this distance should be a goal of adenoma resection. Larger prospective, multi-center studies are necessary to corroborate this finding and establish the effects of distance on hypopituitarism after SRS for pituitary adenomas.

\section{Introduction}

Pituitary adenomas comprise $10-20 \%$ of all primary intracranial tumors, and they are classified into functioning and nonfunctioning adenomas based upon the presence and absence of endocrine secretory activity, respectively. ${ }^{1}$ Resection is often the first-line treatment for functioning adenomas (FA) and larger nonfunctioning adenomas (NFA) with optic nerve compression. ${ }^{2}$ Recurrence or progression occurs in $10-50 \%$ of pituitary adenomas after surgical resection. ${ }^{2,3}$ Stereotactic radiosurgery (SRS) is an important adjuvant and salvage treatment for patients with subtotal resection or recurrence. ${ }^{4,5}$ It has also been used as an upfront treatment for select patients with high surgical risk. ${ }^{4}$

SRS leverages its ability to administer focused, high-dose radiation in a single session while sparing nearby critical neurovascular structures of unwanted radiation. ${ }^{5}$ However, anterior pituitary insufficiency still occurs in 
approximately $18-50 \%$ of patients after SRS for pituitary adenomas. ${ }^{6-8}$ It is the most common intermediate to late complication, with a time-to-onset ranging from 2 months to 14 years after treatment. ${ }^{7,8}$ Hypopituitarism is associated with increased mortality and significant health-related costs. ${ }^{9}, 10$ Higher treatment dose and differences in SRS dose intensities along the hypothalamic-pituitary (HP) axis have been identified as risk factors for post-SRS hypopituitarism. ${ }^{6,11}$ We hypothesize that the distance between the radiosurgical target and the HP axis may be associated with SRS-induced endocrine complications. The aim of this retrospective cohort study was to determine the effects of distance between HP axis neuroanatomical structures and the SRS target volume on anterior pituitary function preservation after SRS for pituitary adenomas.

\section{Methods}

\section{Study design}

Between October 2007 and October 2020, consecutive adult patients who underwent single-session SRS at the University of Virginia Health System for treatment of pituitary adenomas were reviewed. The study was approved by the Institutional Review Board (IRB) committee at our institution and follows the guidelines set forth by the Strengthening the Reporting of Observational Studies in Epidemiology (STROBE) statement. ${ }^{12}$ Data were obtained retrospectively according to a standardized collection protocol, which included a medical chart abstraction and review of SRS planning MRI data.

\section{Patient identification and selection}

The inclusion criteria for this study were: (1) age $\geq 18$ years, (2) available SRS planning MRI data, and (3) $\geq 6$ months of clinical neuroendocrine follow-up. Patients were excluded for the following criteria: (1) whole-sellar SRS, (2) absence of a discrete adenoma, normal pituitary gland or stalk on the SRS planning MRI and (3) history of cranial fractionated radiation therapy before the first SRS treatment. Patients underwent treatment consistent with our institutional standard, which included a comprehensive neuroendocrine assessment comprising clinical evaluation and laboratory testing of adrenocorticotropic hormone (ACTH), cortisol, luteinizing hormone (LH), follicle-stimulating hormone (FSH), insulin-like growth factor-1 (IGF-1), prolactin, thyroid-stimulating hormone (TSH), free thyroxine (T4), 24-hour urinary free cortisol (patients with Cushing's disease), growth hormone (patients with acromegaly), testosterone (males) and estradiol (females $<50$ years) prior to the initial SRS. Patients with subjective visual disturbance or signs of optic apparatus compression were also referred for a formal neuroophthalmological assessment. Routine imaging and neuroendocrine assessments were performed at 6month intervals for the first year, and then yearly until 5 years after SRS. After 5 years, follow-up was performed at 1 to 3-year intervals.

\section{SRS technique}

The SRS technique for treatment of patients with pituitary adenomas at our institution has been previously described. ${ }^{11}$ In brief, a high-resolution MRI was obtained before and after contrast administration, combined with fat suppression, at $1 \mathrm{~mm}$ slice thickness. A Leksell stereotactic Gamma Knife frame was placed under monitored anesthesia care. Following frame placement, a CT was obtained and merged with the high-resolution MRI. Dose planning was performed using the GammaPlan software (Elekta AB, Sweden) by a multidisciplinary team comprising a neurosurgeon, radiation oncologist, and medical physicist. SRS was performed using the Leksell Gamma Knife Unit (Elekta AB, Sweden); the model varied depending upon the time of treatment. 


\section{Clinical data}

Baseline demographic data included age and sex. Medical history data included history of pituitary adenoma resection, history of hypopituitarism, history of central diabetes insipidus, history of visual deficit, presence of a functioning adenoma and duration of clinical neuroendocrine follow-up. SRS planning data included margin dose, treatment volume, and isodose. Hypopituitarism was defined as anterior pituitary hormone deficiency, or requirement of hormone replacement therapy due to pituitary insufficiency. Visual deficit was defined as subjective visual disturbance, evidence of visual field loss, or ocular motility disturbance on formal neuroophthalmological evaluation.

\section{Neuroimaging review}

From the post-contrast fat suppressed dose planning MRI, a single two-dimensional coronal slice with a clearly identifiable pituitary adenoma, pituitary gland and pituitary stalk was selected. The treatment plan was outlined, and distance measurements were made by connecting points between the following structures: (1) edge of the pituitary gland to the prescription isodose line, (2) center of the pituitary gland to the center target within the prescription isodose line, (3) edge of the pituitary gland to the center target within the prescription isodose line, (4) center of the pituitary gland to the prescription isodose line, (5) edge of the pituitary stalk to the prescription isodose line, (6) center of the pituitary stalk to the center target within the prescription isodose line, (7) edge of the pituitary stalk to the center target within the prescription isodose line and (8) center of the pituitary stalk to the prescription isodose line. The MRI was further reviewed for a two-dimensional coronal slice where the adenoma and the hypothalamus were clearly identifiable. Additional distance measurements were made by connecting points between the following structures: (9) edge of the hypothalamus to the prescription isodose line, (10) center of the hypothalamus to the center target within the prescription isodose line, (11) edge of the hypothalamus to the center target within the prescription isodose line and (12) center of the hypothalamus to the prescription isodose line (Figure 1). All measurements were performed by individuals blinded to clinical information.

\section{Outcomes}

The primary outcome was the preservation of pre-SRS anterior pituitary function. No preservation of pre-SRS anterior pituitary function was defined as a new anterior pituitary hormone deficiency below the expected age and gender specific reference range and a formal diagnosis by the treating endocrinologist, or requirement of a new hormone replacement therapy after the initial SRS. The exception to this was growth hormone deficiency, which was defined as a positive result from provocative testing, or a formal diagnosis by the treating endocrinologist. Patients who underwent repeat resection, SRS or adjuvant cranial fractionated radiation therapy were censored at the time of additional treatment.

\section{Statistical analysis}

Statistical analyses were performed using Stata (version 15.0, College Station, TX). Univariable logistic regression analyses, dichotomized by the primary outcome, compared baseline demographic, medical history, treatment and imaging data. A multivariable logistic regression analysis, initially including all potential predictor variables, with stepwise backward elimination of non-contributory variables $(p>0.10)$, was performed to identify independent predictors of the primary outcome. Statistical models were assessed for goodness-of-fit using the HosmerLemeshow test. Covariates were tested for multicollinearity using tolerance and variance inflation factor, and collinear variables were removed from the final model. An area under the receiver operator characteristic curve 
(AUROC) analysis was performed to assess the discrimination of independent variables included in the multivariable logistic regression model. Cut-off points for distance measurements between HP axis neuroanatomical structures and the SRS target volume were calculated using the Youden's Index (YI). ${ }^{13}$ Accuracy was assessed using sensitivity, specificity, positive predictive value (PPV) and negative predictive value (NPV). Statistical significance was defined as $\mathrm{p}<0.05$, and all tests were two-tailed. Missing data were not imputed.

\section{Results}

\section{Study cohort}

Of the 466 eligible patients, 242 were excluded from the present study (153 patients for whole-sellar SRS, 4 patients for the absence of a discrete pituitary adenoma, pituitary gland or pituitary stalk on the dose planning MRI, 73 patients for $<6$ months of clinical neuroendocrine follow-up, 4 patients for the lack of accessible medical history data, and 8 patients for a history of cranial fractionated radiation therapy, Figure 2). The remaining 224 patients (mean age $50.1 \pm 15.2$ years; $52.2 \%$ female) were categorized by the primary outcome of preservation $(n=168)$ and no preservation $(n=56)$ of pre-SRS anterior pituitary function. $54.5 \%(n=122)$ of the patients had a history of hypopituitarism prior to SRS. The rate of new or worsening hypopituitarism after SRS was $25.0 \%(n=56)$ at a mean and median time to onset of 30.5 (30.0) and 18.0 (6.5-38.5) months, respectively. The affected axis was adrenal in 12 patients $(21.4 \%)$, thyroid in 44 patients $(78.6 \%)$, gonadal in 25 patients (44.6\%) and somatic in 16 patients (28.6\%). More than one axis was affected in 16 patients $(28.6 \%)$. Of the patients who experienced post-SRS gonadotropin deficiency, 11 (44.0\%) were female, 5 of whom (20.0\%) were under the age of 50 . The mean and median clinical follow-up durations were 53.7 (38.0) and 46.0 (17.0-75.0) months, respectively.

\section{Determinants of endocrine outcomes}

Table 1 compares the baseline characteristics between the preservation and no preservation of pre-SRS anterior pituitary function cohorts. Univariable predictors of anterior pituitary function preservation were a greater distance between the center of the pituitary gland and center of the target volume (mean $13.5 \mathrm{vs} .12 .4 \mathrm{~mm} ; \mathrm{OR}=1.097$ [1.000-1.203], $p=0.048)$, a greater distance between the edge of the pituitary gland and the center of the target volume (mean 8.7 vs. 7.5mm; $O R=1.120$ [1.012-1.240], $p=0.028$ ), and a shorter clinical follow-up duration (mean 48.0 vs. 70.6 months; $O R=0.985$ [0.977 - 0.993], $p<0.0001$ ). In the multivariable model, independent predictors of anterior pituitary function preservation were a greater distance between the center of the pituitary gland and center of the target volume $(\mathrm{OR}=1.101$ [1.000-1.213], $\mathrm{p}=0.050)$, and a shorter clinical follow-up duration $(\mathrm{OR}=0.985$ [0.977-0.993], $p<0.0001$ ) (Table 2). 
Table 1

Univariable comparisons of patients with and without anterior pituitary function preservation after SRS. Abbreviations: SRS = stereotactic radiosurgery, DI = central diabetes insipidus, SD = standard deviation, $\%=$ per cent, $\mathrm{Gy}=$ Gray, $\mathrm{n}=$ number, $\mathrm{cm}^{3}=$ cubic centimeters, NE = not estimable.

\begin{tabular}{|c|c|c|c|c|c|}
\hline Baseline Characteristics & $\begin{array}{l}\text { Overall } \\
\text { cohort } \\
(n=224)\end{array}$ & $\begin{array}{l}\text { Preservation } \\
(n=168)\end{array}$ & $\begin{array}{l}\text { No } \\
\text { Preservation } \\
(n=56)\end{array}$ & $\begin{array}{l}\text { Odds ratio } \\
\text { [95\% C.I.] }\end{array}$ & p-value \\
\hline Age, mean years (SD) & $\begin{array}{l}50.1 \\
(15.2)\end{array}$ & $51.1(15.3)$ & $47.1(14.6)$ & $\begin{array}{l}1.017 \\
{[0.993-} \\
1.038]\end{array}$ & 0.093 \\
\hline Female, n (\%) & $\begin{array}{l}117 / 224 \\
(52.2)\end{array}$ & $\begin{array}{l}89 / 168 \\
(53.0)\end{array}$ & $28 / 56(50.0)$ & $\begin{array}{l}1.127 \\
{[0.615-} \\
2.063]\end{array}$ & 0.699 \\
\hline Pre-treatment history & & & & & \\
\hline Functioning adenoma, n (\%) & $\begin{array}{l}199 / 224 \\
(44.2)\end{array}$ & $\begin{array}{l}71 / 168 \\
(42.3)\end{array}$ & $28 / 56(50.0)$ & $\begin{array}{l}0.731 \\
{[0.399-} \\
1.343]\end{array}$ & 0.313 \\
\hline Pre-GKRS visual deficit, n (\%) & $\begin{array}{l}47 / 224 \\
(21.0)\end{array}$ & $\begin{array}{l}34 / 168 \\
(20.2)\end{array}$ & $13 / 56(23.2)$ & $\begin{array}{l}0.839 \\
{[0.406-} \\
1.734]\end{array}$ & 0.636 \\
\hline Pre-GKRS hypopituitarism, n (\%) & $\begin{array}{l}122 / 224 \\
(54.5)\end{array}$ & $\begin{array}{l}90 / 168 \\
(53.6)\end{array}$ & $32 / 56(57.1)$ & $\begin{array}{l}0.865 \\
{[0.470-} \\
1.593]\end{array}$ & 0.642 \\
\hline Pre-GKRS DI, n (\%) & $\begin{array}{l}13 / 224 \\
(5.8)\end{array}$ & $\begin{array}{l}11 / 168 \\
(6.6)\end{array}$ & $2 / 56(3.6)$ & $\begin{array}{l}1.892 \\
{[0.406-} \\
8.808]\end{array}$ & 0.417 \\
\hline Prior surgical resection, $\mathrm{n}(\%)$ & $\begin{array}{l}218 / 224 \\
(97.3)\end{array}$ & $\begin{array}{l}162 / 168 \\
(96.4)\end{array}$ & $56 / 56(100.0)$ & NE & 0.152 \\
\hline SRS parameters & & & & & \\
\hline Margin dose, mean Gy (SD) & $19.7(4.1)$ & $19.5(4.0)$ & $20.4(4.3)$ & $\begin{array}{l}0.946 \\
{[0.879-} \\
1.019]\end{array}$ & 0.146 \\
\hline Treatment volume, mean $\mathrm{cm}^{3}(\mathrm{SD})$ & $3.2(2.0)$ & $3.2(2.1)$ & $3.3(1.8)$ & $\begin{array}{l}0.981 \\
{[0.837-} \\
1.149]\end{array}$ & 0.810 \\
\hline Isodose, mean \% (SD) & $50.0(1.1)$ & $50.1(1.2)$ & $50.0(0.0)$ & $\begin{array}{l}1.057 \\
{[0.750-} \\
1.489]\end{array}$ & 0.751 \\
\hline
\end{tabular}




\begin{tabular}{|c|c|c|c|c|c|}
\hline Baseline Characteristics & $\begin{array}{l}\text { Overall } \\
\text { cohort } \\
(n=224)\end{array}$ & $\begin{array}{l}\text { Preservation } \\
(n=168)\end{array}$ & $\begin{array}{l}\text { No } \\
\text { Preservation } \\
(n=56)\end{array}$ & $\begin{array}{l}\text { Odds ratio } \\
\text { [95\% C.I.] }\end{array}$ & p-value \\
\hline \multicolumn{6}{|l|}{ SRS dose distance } \\
\hline \multirow{2}{*}{$\begin{array}{l}\text { Edge gland - Edge dose, mean mm } \\
\text { (SD) }\end{array}$} & \multirow[t]{2}{*}{$1.1(2.6)$} & \multirow[t]{2}{*}{$1.2(2.8)$} & \multirow[t]{2}{*}{$0.8(2.0)$} & 1.074 & \multirow[t]{2}{*}{0.322} \\
\hline & & & & $\begin{array}{l}{[0.933-} \\
1.236]\end{array}$ & \\
\hline \multirow{2}{*}{$\begin{array}{l}\text { Center gland - Center dose, mean } \\
\text { mm (SD) }\end{array}$} & \multirow[t]{2}{*}{$13.2(3.6)$} & \multirow[t]{2}{*}{$13.5(3.6)$} & \multirow[t]{2}{*}{$12.4(3.2)$} & 1.097 & \multirow[t]{2}{*}{0.048} \\
\hline & & & & $\begin{array}{l}{[1.000-} \\
1.203]\end{array}$ & \\
\hline \multirow{2}{*}{$\begin{array}{l}\text { Edge gland - Center dose, mean } \\
\mathrm{mm}(\mathrm{SD})\end{array}$} & \multirow[t]{2}{*}{$8.4(3.3)$} & \multirow[t]{2}{*}{$8.7(3.5)$} & \multirow[t]{2}{*}{$7.5(2.7)$} & 1.120 & \multirow[t]{2}{*}{0.028} \\
\hline & & & & $\begin{array}{l}{[1.012-} \\
1.240]\end{array}$ & \\
\hline \multirow{2}{*}{$\begin{array}{l}\text { Center gland - Edge dose, mean } \\
\text { mm (SD) }\end{array}$} & \multirow[t]{2}{*}{$5.1(3.2)$} & \multirow[t]{2}{*}{$5.2(3.4)$} & \multirow[t]{2}{*}{$4.8(2.7)$} & 1.047 & \multirow[t]{2}{*}{0.367} \\
\hline & & & & $\begin{array}{l}{[0.947-} \\
1.158]\end{array}$ & \\
\hline \multirow{2}{*}{$\begin{array}{l}\text { Edge stalk - Edge dose, mean mm } \\
\text { (SD) }\end{array}$} & \multirow[t]{2}{*}{$4.2(2.2)$} & \multirow[t]{2}{*}{$4.2(2.3)$} & \multirow[t]{2}{*}{$3.9(2.0)$} & 1.080 & \multirow[t]{2}{*}{0.299} \\
\hline & & & & $\begin{array}{l}{[0.934-} \\
1.250]\end{array}$ & \\
\hline \multirow{2}{*}{$\begin{array}{l}\text { Center stalk - Center dose, mean } \\
\mathrm{mm}(\mathrm{SD})\end{array}$} & \multirow[t]{2}{*}{$12.4(3.1)$} & \multirow[t]{2}{*}{$12.6(3.1)$} & \multirow[t]{2}{*}{$11.9(3.2)$} & 1.066 & \multirow[t]{2}{*}{0.197} \\
\hline & & & & $\begin{array}{l}{[0.967-} \\
1.175]\end{array}$ & \\
\hline \multirow{2}{*}{$\begin{array}{l}\text { Edge stalk - Center dose, mean } \\
\text { mm (SD) }\end{array}$} & \multirow[t]{2}{*}{$11.1(2.8)$} & \multirow[t]{2}{*}{$11.2(2.8)$} & $10.7(2.7)$ & & 0.266 \\
\hline & & & & $\begin{array}{l}{[0.9540} \\
1.186]\end{array}$ & \\
\hline Center stalk - Edge dose, mean & $5.4(2.4)$ & $5.5(2.5)$ & $5.0(2.3)$ & 1.102 & 0.161 \\
\hline & & & & $\begin{array}{l}{[0.962-} \\
1.262]\end{array}$ & \\
\hline Edge hypothalamus - Edge dose, & $8.7(2.9)$ & $8.8(2.8)$ & $8.3(2.9)$ & 1.078 & 0.184 \\
\hline & & & & $\begin{array}{l}{[0.965-} \\
1.203]\end{array}$ & \\
\hline $\begin{array}{l}\text { Center hypothalamus - Center } \\
\text { dose mean mm (SD) }\end{array}$ & $16.5(3.2)$ & $16.5(3.2)$ & $16.6(3.1)$ & 0.995 & 0.922 \\
\hline & & & & $\begin{array}{l}{[0.904-} \\
1.095]\end{array}$ & \\
\hline Edge hypothalamus - Center dose, & $14.8(3.1)$ & $14.8(3.1)$ & $14.7(3.0)$ & 1.019 & 0.707 \\
\hline & & & & $\begin{array}{l}{[0.922-} \\
1.127]\end{array}$ & \\
\hline
\end{tabular}




\begin{tabular}{|c|c|c|c|c|c|}
\hline Baseline Characteristics & $\begin{array}{l}\text { Overall } \\
\text { cohort } \\
(n=224)\end{array}$ & $\begin{array}{l}\text { Preservation } \\
(n=168)\end{array}$ & $\begin{array}{l}\text { No } \\
\text { Preservation } \\
(n=56)\end{array}$ & $\begin{array}{l}\text { Odds ratio } \\
\text { [95\% C.I.] }\end{array}$ & p-value \\
\hline \multirow{2}{*}{$\begin{array}{l}\text { Center hypothalamus - Edge dose, } \\
\text { mean mm (SD) }\end{array}$} & \multirow[t]{2}{*}{$10.6(3.2)$} & \multirow[t]{2}{*}{$10.7(3.2)$} & \multirow[t]{2}{*}{$10.2(3.2)$} & 1.054 & \multirow[t]{2}{*}{0.295} \\
\hline & & & & $\begin{array}{l}{[0.955-} \\
1.164]\end{array}$ & \\
\hline \multicolumn{6}{|l|}{ Follow-up } \\
\hline \multirow[t]{2}{*}{ Clinical, mean months (SD) } & \multirow{2}{*}{$\begin{array}{l}53.7 \\
(38.0)\end{array}$} & \multirow[t]{2}{*}{$48.0(36.0)$} & \multirow[t]{2}{*}{$70.6(39.0)$} & 0.985 & \multirow[t]{2}{*}{$<0.0001$} \\
\hline & & & & $\begin{array}{l}{[0.977-} \\
0.993]\end{array}$ & \\
\hline
\end{tabular}

Table 2

Multivariable model of the independent predictors of anterior pituitary function preservation after SRS.

\begin{tabular}{|llll|}
\hline Preservation & Odds ratio & $95 \%$ C.I. & p-value \\
\hline Center gland - Center dose & 1.101 & $1.000-1.213$ & 0.050 \\
\hline Clinical follow-up & 0.985 & $0.977-0.993$ & $<0.0001$ \\
\hline Abbreviations: SRS = stereotactic radiosurgery, C.I. = confidence interval, \% = per cent. \\
\hline
\end{tabular}

\section{Effects of distance on endocrine outcomes}

The adjusted AUROC for the distance between the center of the pituitary gland and center of the target volume in predicting anterior pituitary function preservation was 0.595 (0.506-0.684) (Table 3 , and Figure 3 ). The optimal cutoff distance between these structures in predicting anterior pituitary function preservation was $15.0 \mathrm{~mm}(\mathrm{YI}=0.173)$. The sensitivity, specificity, PPV and NPV in predicting anterior pituitary function preservation at distance of $15 \mathrm{~mm}$ between the center of the pituitary gland and the center of the target volume were $30.0 \%, 88.0 \%, 89.9 \%$, and $26.2 \%$, respectively. Preservation of anterior pituitary function was observed at a distance of $0-5 \mathrm{~mm}$ in 0 of 1 patient (0.0\%), $5-10 \mathrm{~mm}$ in 24 of 37 patients $(64.9 \%), 10-15 \mathrm{~mm}$ in 92 of 126 patients $(73.0 \%), 15-20 \mathrm{~mm}$ in 42 of 49 patients (85.7\%), 20-25mm in 9 of 10 patients (90.0\%), and 25-30mm in 1 of 1 patient (100.0\%) (Figure 4).

Table 3

AUROC analysis identifying the optimal cutoff distance predictive of anterior pituitary function preservation after SRS. Abbreviations: SRS = stereotactic radiosurgery, AUROC = Area under the receiver operator characteristic curve, $\mathrm{YI}=$ Youden Index, $\mathrm{PPV}=$ positive predictive value, $\mathrm{NPV}=$ negative predictive value, $\mathrm{Cl}=$ confidence interval, $\mathrm{SD}=$ standard deviation, \% = per cent.

\begin{tabular}{|c|c|c|c|c|c|c|c|c|c|}
\hline $\begin{array}{l}\text { Preservation } \\
(n=174)\end{array}$ & $\begin{array}{l}\text { No } \\
\text { preservation } \\
(n=56)\end{array}$ & AUROC & $\begin{array}{l}95 \% \\
\mathrm{Cl}\end{array}$ & $\begin{array}{l}\text { Optimal } \\
\text { cut-off, } \\
(\mathrm{mm})\end{array}$ & $\mathrm{YI}$ & $\begin{array}{l}\text { Sensitivity } \\
\text { (\%) }\end{array}$ & $\begin{array}{l}\text { Specificity } \\
\text { (\%) }\end{array}$ & $\begin{array}{l}\text { PPV } \\
(\%)\end{array}$ & $\begin{array}{l}\text { NPV } \\
\text { (\%) }\end{array}$ \\
\hline $\begin{array}{l}\text { Mean } \\
\text { distance } \pm \\
\text { SD (mm) }\end{array}$ & $\begin{array}{l}\text { Mean } \\
\text { distance } \pm \\
\text { SD }(\mathrm{mm})\end{array}$ & & & & & & & & \\
\hline $13.5 \pm 3.6$ & $12.4 \pm 3.2$ & 0.595 & $\begin{array}{l}0.506 \\
-0.684\end{array}$ & 15.0 & 0.173 & 30.0 & 88.0 & 89.9 & 26.2 \\
\hline
\end{tabular}




\section{Illustrative case demonstrating dose fall off as a function of distance between structures}

A 60-year-old female was found to have a non-functioning pituitary adenoma after presenting with pituitary apoplexy in 2009. She underwent three transsphenoidal resections, first in January 2010, second in July 2011 for tumor recurrence, and third in April 2016 for tumor recurrence. Prior to her third resection, her visual and endocrine functions were intact. She underwent adjuvant SRS in September 2016 for residual tumor in the cavernous sinus. In December 2017, she developed cortisol insufficiency and was placed on hydrocortisone replacement. To date, she has experienced no further side effects from treatment and no evidence of tumor recurrence. Figure $5 \mathrm{~A}$ depicts the dose plan utilized at the time of her treatment. The distance between the center of the gland and the center of the SRS target was $9.2 \mathrm{~mm}$. Figure 5B depicts an alternative plan utilizing a steeper fall off in dose towards the pituitary gland and stalk, thereby better shielding these structures from unwanted radiation dose. This may be considered in patients undergoing SRS dose planning with less than $15 \mathrm{~mm}$ between the center of the pituitary gland and the center of the SRS target volume.

\section{Discussion}

Resection is frequently the first-line treatment for symptomatic pituitary adenomas. ${ }^{14}$ The prevalence of preoperative hypopituitarism in patients undergoing surgical resection ranges from $70-85 \%$, and the incidence of new or worsening post-operative hypopituitarism ranges from 5-15\%. ${ }^{15-17}$ SRS offers adjuvant or salvage treatment for those with subtotal resection or recurrence, and an alternative to surgical resection for patients with high surgical risks. ${ }^{4,14}$ The incidence of hypopituitarism after SRS, reported to range from $18-50 \%$, is lower than the reported rates of $30-100 \%$ after fractionated radiotherapy. ${ }^{6-8,11,18-22}$ However, pituitary insufficiency remains the most common adverse effect after SRS for pituitary adenomas. ${ }^{6,8}$ Hypopituitarism is associated with significant morbidity, increased mortality, poorer quality of life, and greater health related costs. ${ }^{9,10,23-25}$ Given the frequent utilization of SRS as an adjuvant post-surgical treatment, identification of solutions to minimize the risk of new or worsening hypopituitarism after SRS for pituitary adenomas is critical.

In this study, we sought to identify relationships between HP axis to SRS target volume distances and anterior pituitary function preservation after SRS. We identified that a greater distance between the center of the pituitary gland and the center of the SRS target volume was an independent predictor of anterior pituitary function preservation. Based upon these findings, we performed an AUROC analysis to generate a predictive tool for anterior pituitary function preservation. A distance of $15 \mathrm{~mm}$ between the center of the gland and the center of the SRS target volume was associated with a specificity of $88 \%$ and PPV of $90 \%$ for anterior pituitary function preservation. Taken together, our observations suggest that distances of $15 \mathrm{~mm}$ or greater between the center of the gland and the center of the SRS target are associated with anterior pituitary function preservation, whereas distances of less than $15 \mathrm{~mm}$ may be associated with new or worsening hypopituitarism after SRS. Thus, a minimum $15 \mathrm{~mm}$ distance between the pituitary gland and any residual adenoma should be a goal of resections undertaken prior to SRS.

We also found an independent association between shorter clinical follow-up duration and anterior pituitary function preservation after SRS. This finding likely reflects a delay in the onset of SRS treatment-related hormonal adverse effects. ${ }^{6,8}$ In our patient cohort, the median time to onset of new or worsening hypopituitarism was 18 months (IQR 6.5 - 36.5 months) after SRS. This was consistent with previous reports, which ranged between 21 
and 120 months after SRS. $8,11,22,26-28$ The time to development of new endocrinopathy may also depend upon the affected hormone. In a cohort of 48 non-functioning adenoma patients treated with SRS, Gopalan et al. reported early onset of cortisol deficiency at a mean of 27 months, compared to gonadotropin deficiency, which occurred a mean of 120 months after SRS. ${ }^{22}$ Thyroid hormone and growth hormone deficiency occurred at a mean of 40 and 71 months after SRS, respectively. While the majority new endocrinopathies develop within 5 years after SRS, lateonset hypopituitarism can occur in approximately $15 \%$ of cases. ${ }^{8}$ In the context of the present study, these observations underscore the need for continued longitudinal endocrine follow-up in SRS-treated pituitary adenoma patients.

Treatment dose is a previously described risk factor for new hypopituitarism after SRS for pituitary adenomas. ${ }^{8,11,}$ $21,28,29$ Furthermore, higher doses to the pituitary gland or the pituitary stalk have been found to independently predict development of pituitary insufficiency after SRS. ${ }^{11,21,29}$ Therefore, to mitigate these adverse radiation effects, Taussky et al. proposed the placement of a fat graft between the residual tumor and the normal gland at the time of surgery among patients expected to undergo adjuvant SRS or fractionated radiation therapy. ${ }^{14}$ In their patient cohort, there were no new cases of pituitary insufficiency observed over a median follow-up period of 4 years, substantiating their hypothesis that a greater distance between the two anatomical structures can preserve anterior pituitary function after SRS. Our observation of an association between the distance from the center of the pituitary gland to the center of the SRS treatment target and new hypopituitarism may be related to the effects of radiation dose delivery to surrounding structures. Given that radiation falls off via an inverse square law, the dose fall off is proportional to the inverse of the square of the distance. Knowledge of this relationship between dose and distance should be utilized during pituitary adenoma resection to safely maximize the distance between the two structures among patients expected to undergo adjuvant SRS. In patients with smaller distances between SRS target and normal pituitary gland, a steeper dose fall off towards the gland through the use of advanced radiosurgical planning techniques should be emphasized to preserve anterior pituitary function.

\section{Limitations}

There are a number of limitations to this study which must be acknowledged. Most importantly, our retrospective study design is subject to confirmation bias, in that variables were chosen based upon data availability and hypothesis generation. Our results are contingent upon the accuracy of reported data, which was largely based upon medical chart abstraction. Furthermore, the power of our analysis was limited by the relatively small number of patients who developed new or worsening hypopituitarism. Measurements between the SRS treatment target and HP axis structures may be subject to restricted generalizability and measurement bias. Loss to follow-up may have contributed to selection bias, resulting in outcome differences. While this was adjusted for in our analyses, it is not possible to entirely account for the possibility of late-onset hypopituitarism in patients with insufficient follow-up. Additional limitations include reporting, recall and missing data biases, due to the sourcing of the study data from a single center. Finally, our AUROC analysis found the distance between the gland and the SRS target to be a weak predictor of anterior pituitary function preservation.

\section{Conclusions}

Greater distance between the center of the pituitary gland and the center of the SRS target volume appears to be associated with anterior pituitary function preservation after SRS for pituitary adenomas. A distance of $15 \mathrm{~mm}$ or more between the center of the pituitary gland and the center of the SRS target volume predicts anterior pituitary

Page $10 / 18$ 
function preservation. This finding underscores the importance of dose and distance in SRS radiosurgical planning and the relevance of maximizing the distance between the pituitary gland and the residual adenoma during resection. Larger prospective, multi-center studies are necessary and underway to corroborate this finding and determine the effects of distance on hypopituitarism after SRS for pituitary adenomas.

\section{Declarations}

\section{Statements and Declarations:}

The authors declare no competing interests.

\section{Abstract word count: 275}

Text word count: 2,995

Figures/Tables: Figures: 5, Tables: 3

\section{Author contributions:}

All authors contributed to the study conception and design. Material preparation, data collection and analysis was performed by Natasha Ironside. Statistical guidance was provided by Zhiyuan Xu and Ching-Jen Chen. The first draft of the manuscript was written by Natasha Ironside and all authors commented on previous versions of the manuscript. All authors read and approved the final manuscript.

\section{Data availability}

This study data is available from the corresponding author upon reasonable request.

\section{Compliance with ethical standards:}

Ethical approval: This article utilizes retrospective data and does not contain any studies with human participants performed by any of the authors.

\section{Conflict of interest:}

The authors declare no conflict of interest.

\section{Funding:}

No funding was obtained for this study.

\section{References}

1. Ezzat S, Asa SL, Couldwell WT, et al. The prevalence of pituitary adenomas: a systematic review. Cancer 2004;101:613-619.

2. Hayhurst C, Taylor PN, Lansdown AJ, Palaniappan N, Rees DA, Davies JS. Current perspectives on recurrent pituitary adenoma: The role and timing of surgery vs adjuvant treatment. Clin Endocrinol (Oxf) 2020;92:89-97. 
3. Dekkers OM, Pereira AM, Roelfsema F, et al. Observation alone after transsphenoidal surgery for nonfunctioning pituitary macroadenoma. J Clin Endocrinol Metab 2006;91:1796-1801.

4. Castro DG, Cecílio SA, Canteras MM. Radiosurgery for pituitary adenomas: evaluation of its efficacy and safety. Radiat Oncol 2010;5:109.

5. Ding D, Starke RM, Sheehan JP. Treatment paradigms for pituitary adenomas: defining the roles of radiosurgery and radiation therapy. J Neurooncol 2014;117:445-457.

6. Kotecha R, Sahgal A, Rubens M, et al. Stereotactic radiosurgery for non-functioning pituitary adenomas: metaanalysis and International Stereotactic Radiosurgery Society practice opinion. Neuro Oncol 2020;22:318-332.

7. Zibar Tomšić K, Dušek T, Kraljević I, et al. Hypopituitarism after gamma knife radiosurgery for pituitary adenoma. Endocr Res 2017;42:318-324.

8. Cordeiro D, Xu Z, Mehta GU, et al. Hypopituitarism after Gamma Knife radiosurgery for pituitary adenomas: a multicenter, international study. J Neurosurg 2018.

9. Ehrnborg C, Hakkaart-Van Roijen L, Jonsson B, Rutten FF, Bengtsson BA, Rosén T. Cost of illness in adult patients with hypopituitarism. Pharmacoeconomics 2000;17:621-628.

10. Tomlinson JW, Holden N, Hills RK, et al. Association between premature mortality and hypopituitarism. West Midlands Prospective Hypopituitary Study Group. Lancet 2001;357:425-431.

11. Pomeraniec IJ, Taylor DG, Cohen-Inbar O, Xu Z, Lee Vance M, Sheehan JP. Radiation dose to neuroanatomical structures of pituitary adenomas and the effect of Gamma Knife radiosurgery on pituitary function. J Neurosurg 2019;132:1499-1506.

12. von Elm E, Altman DG, Egger M, Pocock SJ, Gøtzsche PC, Vandenbroucke JP. The Strengthening the Reporting of Observational Studies in Epidemiology (STROBE) statement: guidelines for reporting observational studies. Lancet 2007;370:1453-1457.

13. Youden WJ. Index for rating diagnostic tests. Cancer 1950;3:32-35.

14. Taussky P, Kalra R, Coppens J, Mohebali J, Jensen R, Couldwell WT. Endocrinological outcome after pituitary transposition (hypophysopexy) and adjuvant radiotherapy for tumors involving the cavernous sinus. J Neurosurg 2011;115:55-62.

15. Nomikos P, Ladar C, Fahlbusch R, Buchfelder M. Impact of primary surgery on pituitary function in patients with non-functioning pituitary adenomas - a study on 721 patients. Acta Neurochir (Wien) 2004;146:27-35.

16. Kelly DF, Fatemi N, Dusick J. Pituitary Hormonal Loss and Recovery After Transsphenoidal Adenoma Removal. Neurosurgery 2010;67:E221.

17. Alexopoulou O, Everard V, Etoa M, et al. Outcome of pituitary hormone deficits after surgical treatment of nonfunctioning pituitary macroadenomas. Endocrine 2021;73:166-176.

18. Toogood AA. Endocrine consequences of brain irradiation. Growth Horm IGF Res 2004;14 Suppl A:S118-124. 
19. Darzy KH. Radiation-induced hypopituitarism after cancer therapy: who, how and when to test. Nat Clin Pract Endocrinol Metab 2009;5:88-99.

20. Li X, Li Y, Cao Y, et al. Safety and efficacy of fractionated stereotactic radiotherapy and stereotactic radiosurgery for treatment of pituitary adenomas: A systematic review and meta-analysis. J Neurol Sci 2017;372:110-116.

21. Oh JW, Sung KS, Moon JH, et al. Hypopituitarism after Gamma Knife surgery for postoperative nonfunctioning pituitary adenoma. J Neurosurg 2018;129:47-54.

22. Gopalan R, Schlesinger D, Vance ML, Laws E, Sheehan J. Long-term outcomes after Gamma Knife radiosurgery for patients with a nonfunctioning pituitary adenoma. Neurosurgery 2011;69:284-293.

23. Webb SM, Crespo I, Santos A, Resmini E, Aulinas A, Valassi E. MANAGEMENT OF ENDOCRINE DISEASE: Quality of life tools for the management of pituitary disease. Eur J Endocrinol 2017;177:R13-r26.

24. Zhang J, Wang Y, Xu X, Gu Y, Huang F, Zhang M. Postoperative complications and quality of life in patients with pituitary adenoma. Gland Surg 2020;9:1521-1529.

25. Johnson MD, Woodburn CJ, Vance ML. Quality of life in patients with a pituitary adenoma. Pituitary 2003;6:8187.

26. Feigl GC, Pistracher K, Berghold A, Mokry M. Pituitary insufficiency as a side effect after radiosurgery for pituitary adenomas: the role of the hypothalamus. J Neurosurg 2010;113 Suppl:153-159.

27. Yu J, Li Y, Quan T, et al. Initial Gamma Knife radiosurgery for nonfunctioning pituitary adenomas: results from a 26-year experience. Endocrine 2020;68:399-410.

28. Xu Z, Lee Vance M, Schlesinger D, Sheehan JP. Hypopituitarism after stereotactic radiosurgery for pituitary adenomas. Neurosurgery 2013;72:630-637; 636-637.

29. Feigl GC, Bonelli CM, Berghold A, Mokry M. Effects of gamma knife radiosurgery of pituitary adenomas on pituitary function. J Neurosurg 2002;97:415-421.

\section{Figures}



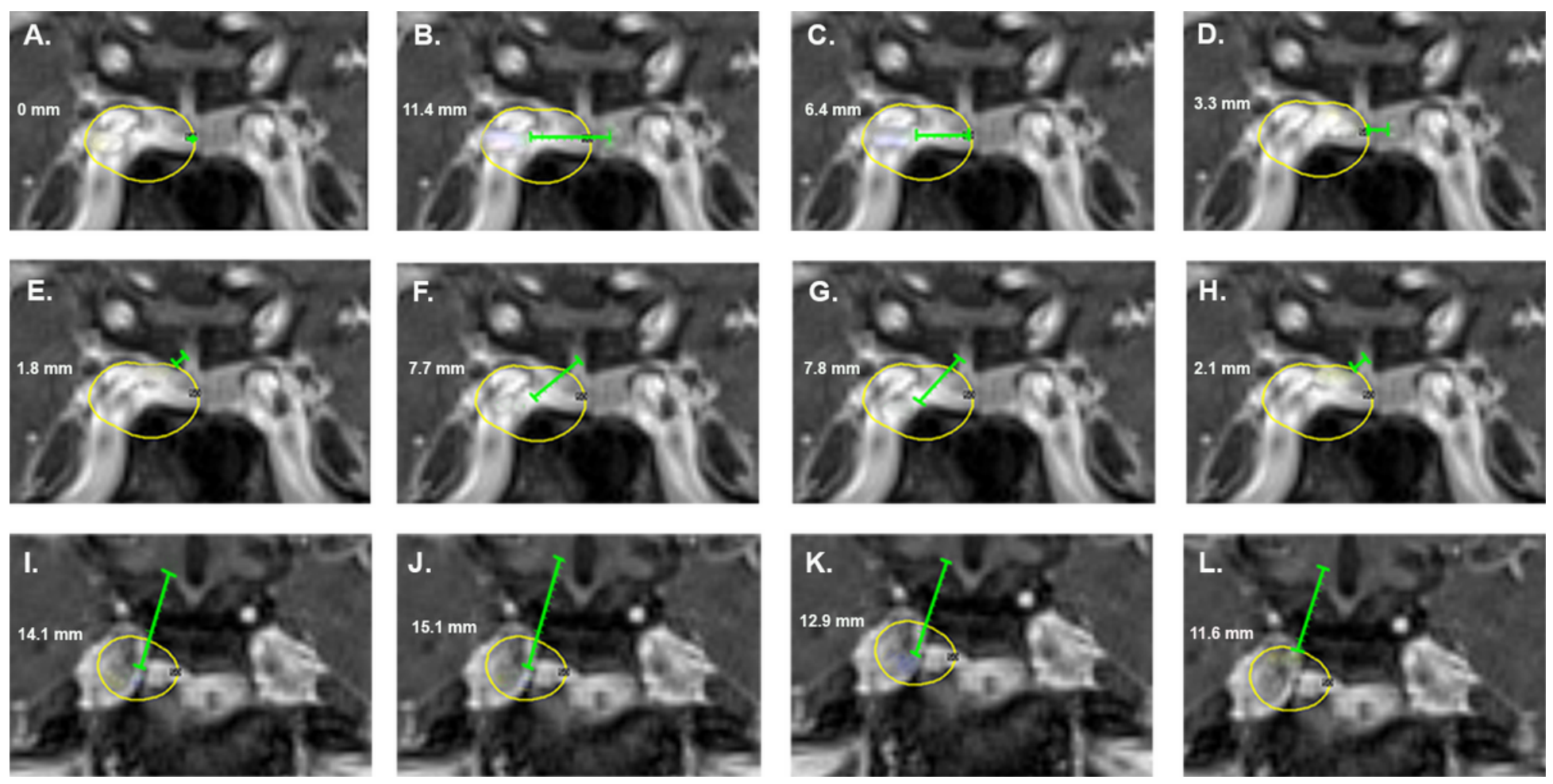

\section{Figure 1}

Representative images of the SRS dose to HP axis distance measurements. (A) edge of the pituitary gland to the prescription isodose line, $(B)$ center of the pituitary gland to the center target, $(C)$ edge of the pituitary gland to the center target, (D) center of the pituitary gland to the prescription isodose line, (E) edge of the pituitary stalk to the prescription isodose line, $(F)$ center of the pituitary stalk to the center target, $(G)$ edge of the pituitary stalk to the center target, $(\mathrm{H})$ center of the pituitary stalk to the prescription isodose line, $(\mathrm{I})$ edge of the hypothalamus to the prescription isodose line, $(\mathrm{J})$ center of the hypothalamus to the center target, $(\mathrm{K})$ edge of the hypothalamus to the center target, $(\mathrm{L})$ center of the hypothalamus to the prescription isodose line. Contouring: Yellow = prescription isodose line. Abbreviations: SRS = stereotactic radiosurgery, HP = hypothalamic pituitary. 


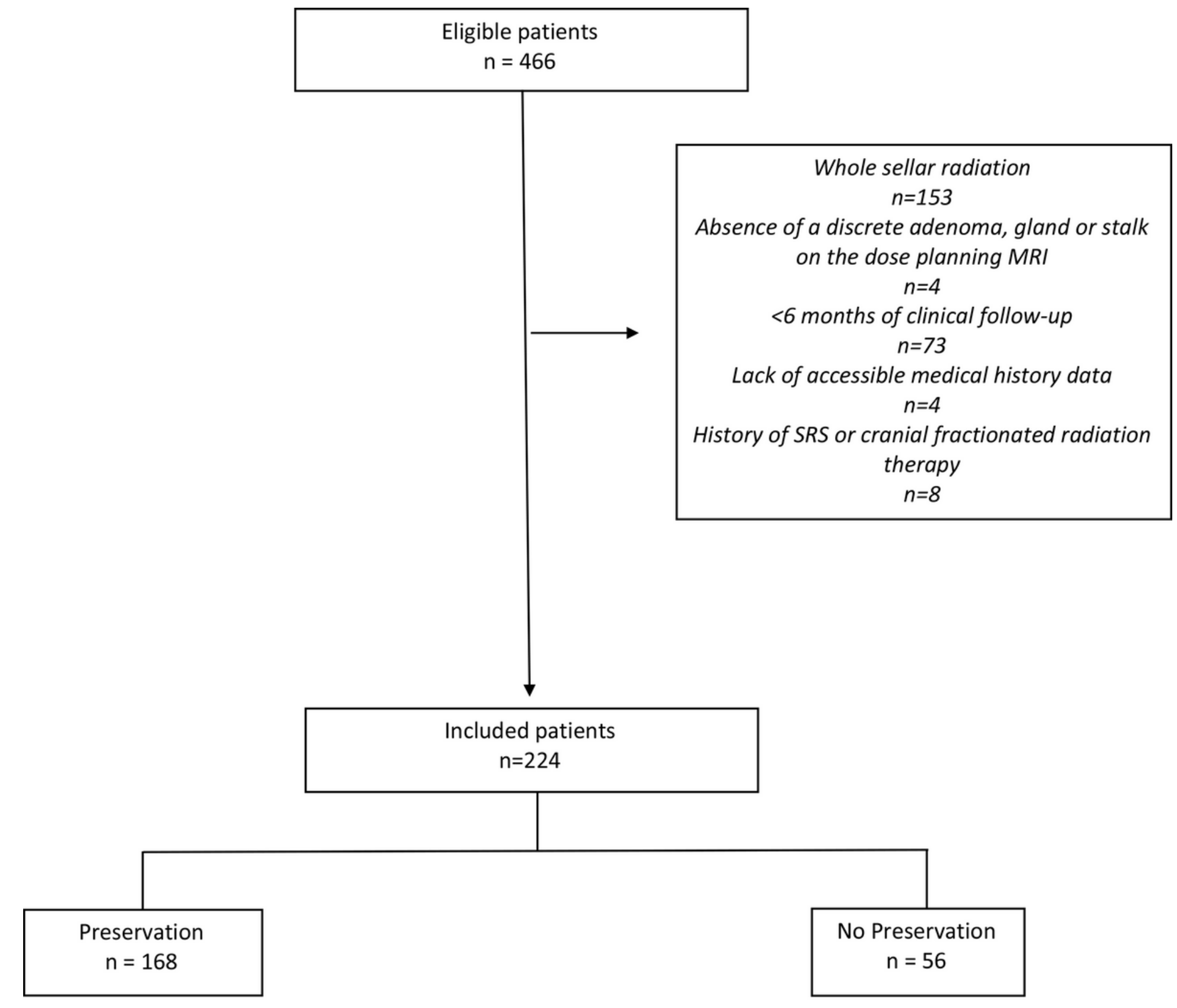

Figure 2

Flow chart of the patient selection process. Abbreviations: SRS = stereotactic radiosurgery, MRI = magnetic resonance imaging. 


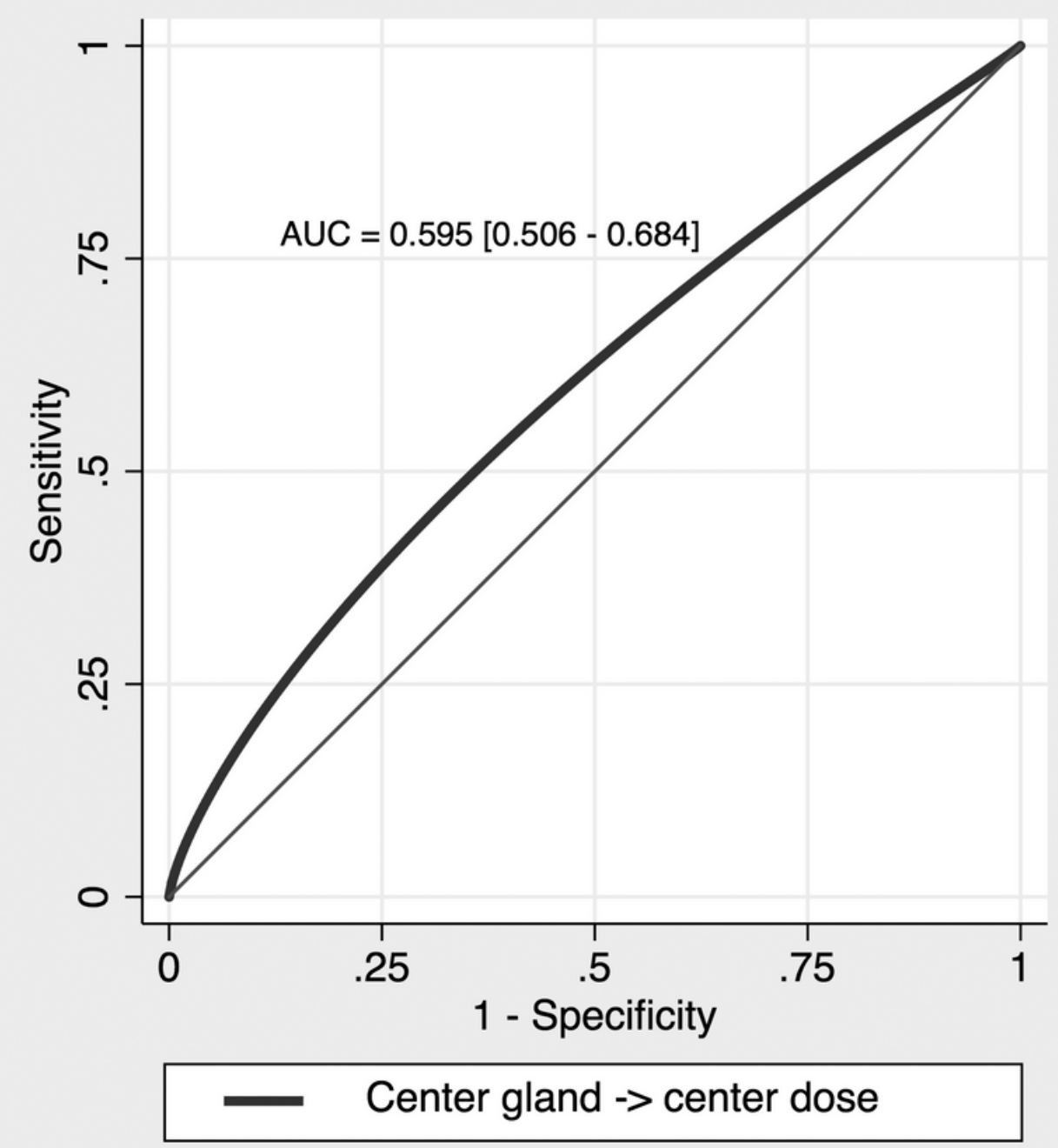

Figure 3

Adjusted AUROC of the distance between the center of the pituitary gland and the center of the SRS target in predicting anterior pituitary function preservation. Abbreviations: AUROC/AUC $=$ area under the receiver operator curve, SRS = stereotactic radiosurgery. 


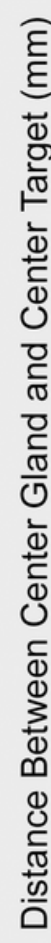

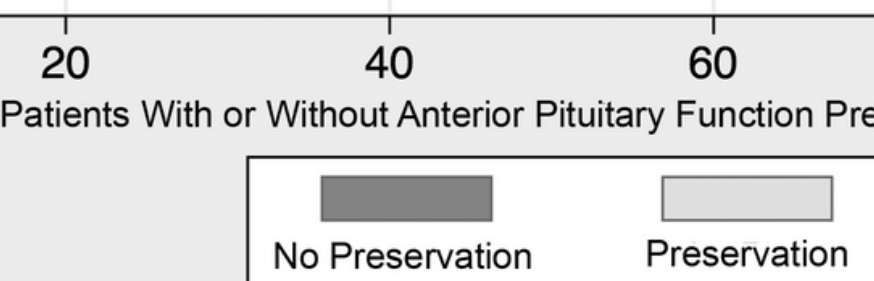

\section{Figure 4}

Relationship between distance from the center of the pituitary gland and the center of the SRS target and anterior pitutary function preservation.
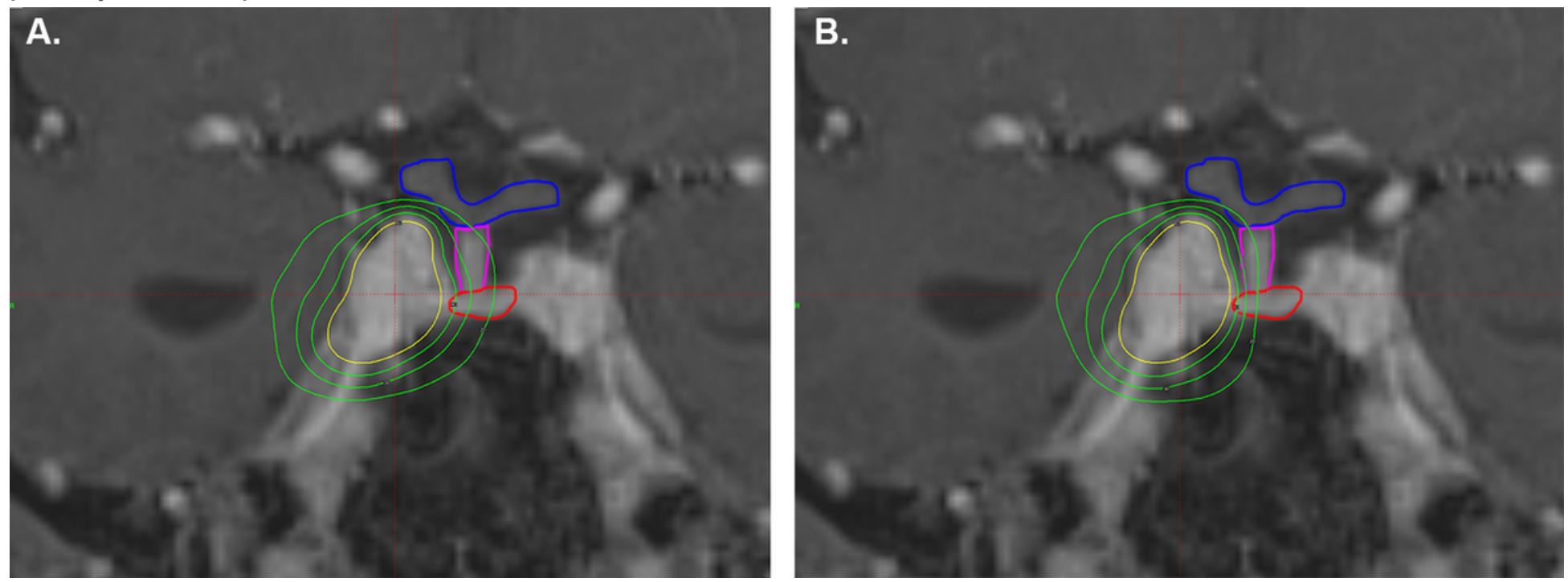

\section{Figure 5}


(A) Representative SRS dose plan for the treatment of residual pituitary adenoma in the cavernous sinus. The distance between the center of the pituitary gland and the center of the SRS target is $9.2 \mathrm{~mm}$. (B) Alternative dose plan demonstrating a steeper dose fall off in the direction of the pituitary gland and stalk. Contouring: Yellow = prescription and in this case $50 \%$ isodose line, green $=20 \%$ isodose line, red = pituitary gland, pink = pituitary stalk, blue $=$ optic apparatus . 